\title{
In vivo molecular sensing in diabetes mellitus: an implantable glucose sensor with direct electron transfer
}

\author{
J.C. Pickup, G. W. Shaw and D. J.Claremont \\ Division of Chemical Pathology, United Medical and Dental Schools of Guy's and St Thomas's Hospitals, Guy's Hospital, London, UK
}

\begin{abstract}
Summary. Miniature, amperometric glucose sensors were constructed for implantation in the subcutaneous tissue of normal and insulin-dependent diabetic subjects. To minimise dependence on fluctuating tissue oxygen tension, we employed the technology of mediated electron transfer, with $1,1^{\prime}$-dimethylferrocene acting as the redox shuttle between immobilized glucose oxidase and a platinum base electrode. In 6 normal subjects, the subcutaneous sensor responses mirrored the simultaneously-measured changes in blood glucose concentration after a $75 \mathrm{~g}$ oral glucose load and after intravenous injection of $0.15 \mathrm{U} / \mathrm{kg}$ short-acting insulin, though increases and decreases in the sensor output were slower than the glycaemic changes. The mean peak delay in sensor response after the oral glucose was $40 \mathrm{~min}$ (range $0-45 \mathrm{~min}$ ) and the delay in
\end{abstract}

the hypoglycaemic nadir was $4 \mathrm{~min}$ (range $0-15 \mathrm{~min}$ ). In 5 insulin-dependent diabetic subjects, spontaneous and induced hypoglycaemia was detectable by the implanted sensor. In addition, marked and frequent oscillations in the sensor current occurred in several normal and diabetic individuals as the blood glucose fell below about $1.9 \mathrm{mmol} / 1$. These oscillations were present in a diabetic subject who had lost adrenergic warning symptoms to hypoglycaemia. Continuous metabolic monitoring in diabetes, particularly the detection of hypoglycaemia, may be possible with implanted sensors based on this technology.

Key words: Glucose sensor, enzyme electrode, biosensor, glucose oxidase, ferrocene, diabetes mellitus.
Implantable biosensors are being developed for use in clinical medicine because they allow continuous measurement of rapidly varying analytes, without the need for added reagents or withdrawal of body fluids [1]. An in vivo glucose sensor for use in insulin-dependent diabetes is a major application for this technology because the signal could be used for feedback-control of a portable insulin infusion pump and maintenance thereby of long-term near-normoglycaemia.

However, a more feasible and equally valuable goal for the immediate future is the development of an implantable sensor which could act as an hypoglycaemia alarm over a relatively short period of time, such as overnight. Hypoglycaemia is a common and much feared complication of diabetes; the many patients who have lost the adrenergic warning symptoms of hypoglycaemia [2] would particularly benefit from such a device.

We have recently evaluated in animals [3] a new technology for glucose sensing which employs a low molecular weight redox couple (ferrocene) to shuttle electrons between an immobilized enzyme (glucose oxidase) and a base electrode (Fig.1). Because the physiological electron acceptor for glucose oxidase, dioxygen, is not involved in the reaction, the sensor may be more suitable for implantation at sites such as the subcutaneous tissue where changing $\mathrm{PO}_{2}$ may affect the output of the more conventional types of glucose sensor, such as those based on the detection of hydrogen peroxide production or oxygen consumption [1]. Further, we have described a modification of the ferrocene technology in which miniature sensors suitable for implantation in man were rendered completely drift-free over an $18 \mathrm{~h}$ period by the covalent attachment of glucose oxidase to agarose beads $[4,5]$.

We report here studies in which ferrocene-mediated glucose sensors have been implanted for the first time in insulin-dependent diabetic patients, and for comparison in a group of normal subjects. This demonstrates the feasibility of short-term metabolic monitoring and the potential for detection of hypoglycaemia by this method. 


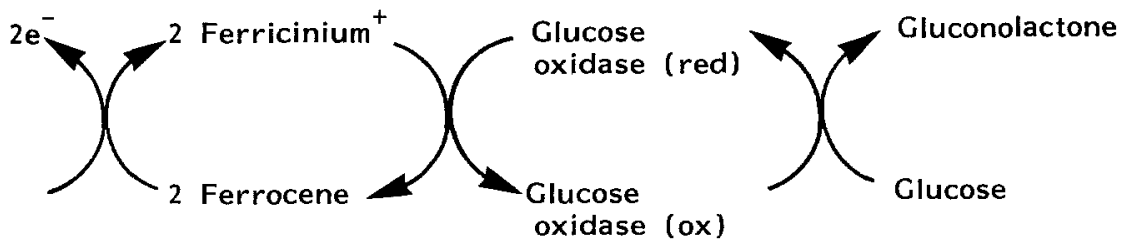

Fig. 1. The mechanism of action of ferrocene - mediated glucose sensors

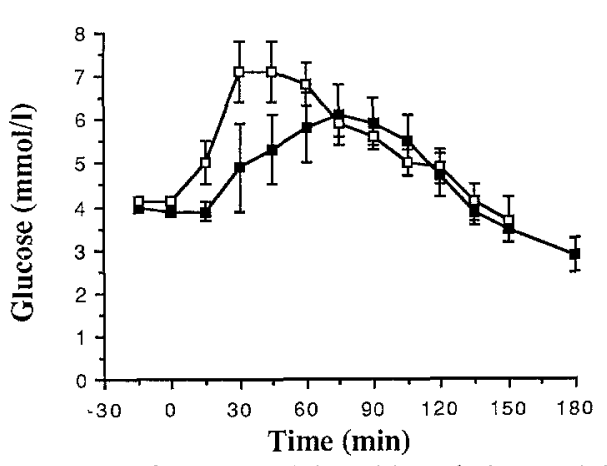

Fig. 2. In vivo sensor (四) and blood glucose (ㅁ) concentrations in 6 normal subjects given a $75 \mathrm{~g}$ oral glucose load at time 0

\section{Materials and methods}

\section{Sensors}

Glucose sensors were constructed by a modification of the procedure described previously $[4,5]$. The base electrode was platinum wire (0.46 mm diameter, BDH Chemicals Ltd, Poole, UK) which was inserted into a 22 gauge Teflon cannula (Viggo AB, Helsingborg, Sweden) so as to leave an approximately $0.5 \mathrm{~mm}$ chamber at one end. The cannula was sealed to the wire at the other end with epoxy resin (RS Components, Corby, Northants, UK). The chamber was then filled with a paste consisting of equal parts of glucose oxidase (Sturge Ltd, Selby, Yorks, UK) immobilised to agarose beads (cyanogen bromide activated Sepharose 4B, Sigma Chemicals Ltd, Poole, Dorset, UK) and Ultracarbon $F$ powder (Johnson Matthey Chemicals, Royston, UK) which had been presoaked in 1,1'-dimethylferrocene solution $(20 \mathrm{mg} / \mathrm{ml}$ in ethanol, $10 \mu \mathrm{l} / \mathrm{mg}$ carbon, (Strem Chemicals, Inc, Newburyport, Mass, USA) and allowed to dry. Cellulose dialysis membrane (Visking, Medicell International, London, UK) was stretched over the sensing tip and held in place with an outer 18 gauge cannula (Venflon, Viggo AB).

\section{Subjects and protocol}

Six normal subjects ( 5 males, age $25-44$ years) volunteered for a study in which one or two glucose sensors were implanted approximately $5 \mathrm{~cm}$ apart in the subcutaneous tissue of the forearm and responses compared with blood glucose concentrations before and after a $75 \mathrm{~g}$ oral glucose load. Sensors were introduced after local anaesthesia with $1 \%$ lignocaine solution and puncture of the skin with a 17 gauge needle. Blood samples were taken from an indwelling Teflon cannula in an antecubital vein which was kept patent with heparinised $0.154 \mathrm{~mol} / 1 \mathrm{NaCl}$. Glucose concentrations were measured using a Yellow Springs Instruments glucose analyser, Model $23 \mathrm{M}$ (Yellow Springs, Ohio, USA). Subjects were sitting during the test.

On a separate occassion, 6 normal subjects ( 5 males, age $25-40$ years) took part in a study in which one or two glucose sensors were implanted in the subcutaneous tissue as above, except that blood glucose concentrations were deliberately lowered by the i.v. injection of $0.15 \mathrm{U} / \mathrm{kg}$ short - acting insulin. Glucose levels were restored $25 \mathrm{~min}$ after insulin injection by the i. v. injection of $50 \mathrm{ml}$ of $50 \%$ (weight/volume) glucose solution. Subject were supine during the test.

Five insulin-dependent diabetic patients $(3 \mathrm{male})$ were also recruited for trial of the sensor. Their mean \pm SD age was $41 \pm 10$ years, the mean duration of diabetes was $22 \pm 9$ years, and the pre-study mean insulin dosage was $40 \pm 14 \mathrm{U} /$ day.

Patients attended a metabolic ward and were either studied for approximately $4 \mathrm{~h}$ whilst they were receiving their usual insulin regimen and eating meals according to their usual diet (in the sitting position), or during controlled induction of hypoglycaemia. For the latter, shortacting insulin was infused $i . v$. at the rate of $6 \mathrm{U} / \mathrm{h}$ using a syringe pump (Treonic IP3, Vickers Medical, Basingstoke, UK), and blood samples taken at 5-10 min intervals for glucose assay. Twenty-five min after insulin injection, $25 \mathrm{~g}$ of glucose $(50 \mathrm{ml}$ of $50 \% \mathrm{w} / \mathrm{v})$ was injected i.v. to restore near-normoglycaemia. Electrodes were implanted for both studies in the subcutaneous tissue of the forearm and venous blood samples taken, as for non-diabetic subjects. In all studies, glucose sensors were held at $160 \mathrm{mV}$ under potentiostatic control (Ministat, Thompson Electrochem Ltd, Newcastle-upon-Tyne, UK) and currents recorded on a dual-channel LKB Model 2210 chart recorder (LKB, Selsdon, UK). The reference electrode was a silver/silver chloride surface EKG electrode (Medicotest, Ølstykke, Denmark) which was attached to the forearm approximately $5 \mathrm{~cm}$ from a working electrode. Working electrodes were calibrated immediately after explantation in glucose solutions made up in $0.1 \mathrm{~mol} / 1$ sodium phosphate buffer $\mathrm{pH} 7.4$ contained in a stirred, thermostatically controlled cell at $37^{\circ} \mathrm{C}$.

The in vitro characteristics of the sensors were similar to those described previously [4], with a mean \pm S.D $95 \%$ response time of $4.2 \pm 2.3 \mathrm{~min}$ after explantation, and a background current $\left(\mathrm{I}_{\mathrm{o}}\right)$ of $33.5 \pm 6.2 \mathrm{nA}$.

\section{Statistical analysis}

Statistical comparison of values was made using the paired t-test. The study was approved by the Guy's Hospital Ethical Committee.

\section{Results}

There was a wide inter-electrode variation in the baseline current of the glucose sensors when implanted in the subcutaneous tissue: the mean \pm SD current (after deduction of background current) at the start of the studies being $66 \pm 32 \mathrm{nA}$ (range $11-115 \mathrm{nA}, n=17$ ). After explantation, the sensors were calibrated in vitro by operation in buffered glucose solutions at $37^{\circ} \mathrm{C}$. The mean ratio of the blood glucose to the in vitro calibrated glucose concentration was 1.8 (range 0.6-4.1). Because of this large variation, the current output of electrodes was routinely calibrated in vivo, approximately $20 \mathrm{~min}$ after implantation, with reference to the steady-state blood glucose value at this time.

Figure 2 shows the blood glucose concentrations measured by a conventional glucose analyser and the responses of subcutaneously implanted glucose sensors 


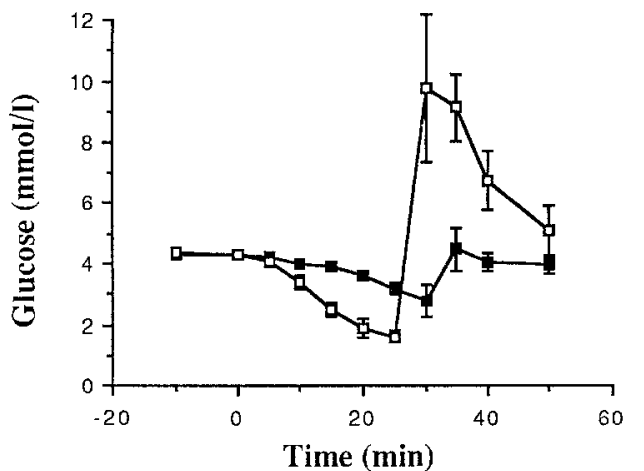

Fig.3. In vivo sensor $(\square)$ and blood glucose $(\square)$ concentrations in 6 normal subjects given $0.15 \mathrm{U} / \mathrm{kg}$ short-acting insulin i.v. at time 0 . After $25 \mathrm{~min}$, hypoglycaemia was terminated by the i.v. injection of 25 g glucose solution

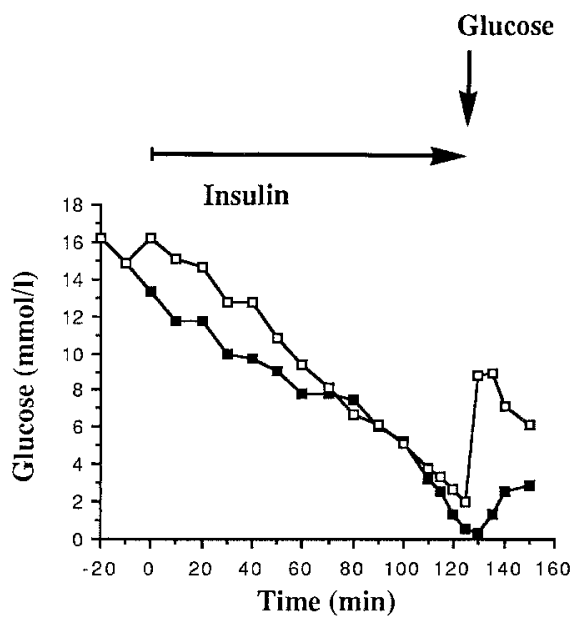

Fig.4. Glucose sensor responses ( $\square$ ) and blood glucose concentrations ( $\square$ ) in a representative diabetic subject in whom hypoglycaemia was induced by the i.v. infusion of short-acting insulin. Hypoglycaemia was terminated by stopping insulin infusion and by the administration of $25 \mathrm{~g}$ glucose solution i. $\mathrm{v}$.

in 6 normal subjects given a $75 \mathrm{~g}$ oral glucose load. The sensor readings from the tissue mirrored the changes in the blood, though the rate of rise was slower than that of the blood glucose concentrations, the peak being delayed by a mean of $40 \mathrm{~min}$ (range $0-45 \mathrm{~min}$ ). In experiments in which two electrodes were implanted, the electrode kinetics were similar and peak responses did not differ by more than $15 \mathrm{~min}$.

Figure 3 shows the in vivo calibrated glucose sensor responses and simultaneously measured blood glucose values in 6 normal subjects given an i.v. bolus of insulin to lower glycaemic values. The sensor recordings again reflected alterations in blood glucose but fell more slowly than blood concentrations, the mean delay in the nadirs being $4 \mathrm{~min}$ (range $0-15 \mathrm{~min}$ ). Blood glucose values were significantly different from baseline by $5 \mathrm{~min}$ after insulin injection $(p=0.04)$ and sensor glucose readings by $10 \mathrm{~min}(p=0.0006)$, and subsequently after administration of $i$. v. glucose, the rise in sensor output was in tandem with, but of lesser magnitude than, the blood glu-
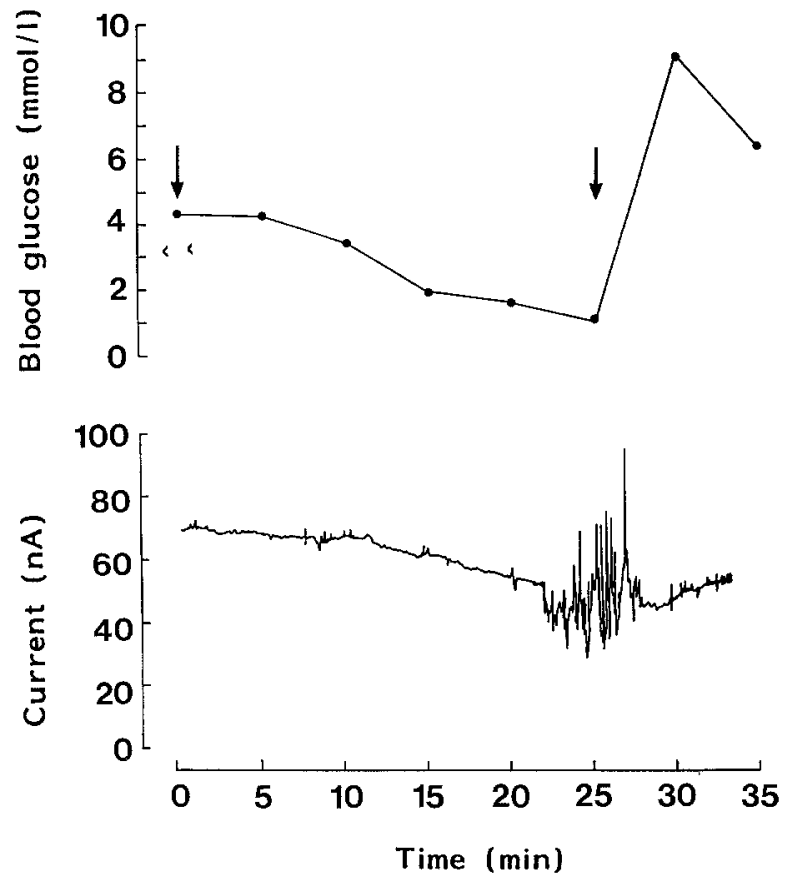

Fig. 5. Blood glucose concentrations $(\bullet)$ and a tracing from the current output of a subcutaneously implanted sensor in a normal subject, demonstrating oscillations of the sensor during hypoglycaemia. First $\downarrow$ indicates time of $i$.v. insulin injection. Second $\downarrow$ indicates time of i.v. glucose injection

cose change. In experiments in which two electrodes were implanted, the rate of fall of electrode responses during hypoglycaemia was similar for both and did not differ by more than $0.08 \mathrm{mmol} \cdot 1^{-1} \cdot \mathrm{min}^{-1}$.

The ability of the sensor to monitor hypoglycaemia was also confirmed in insulin-dependent diabetic subjects who were studied during the occurrence of episodes of spontaneous hypoglycaemia or during controlled hypoglycaemia induced by the i. v. infusion of short-acting insulin. Figure 4 shows the results from a representative study of induced hypoglycaemia.

In 5 of the 6 normal subjects, the sensor current exhibited rapid and marked oscillations at the time of hypoglycaemia, commencing at a time between 20 and $25 \mathrm{~min}$ after insulin administration and corresponding to a mean blood glucose of between 1.9 and $1.6 \mathrm{mmol} / \mathrm{l}$. These oscillations ceased approximately $10-15 \mathrm{~min}$ after the injection of i.v. glucose solution, when the mean blood glucose was $6.8-9.2 \mathrm{mmol} / \mathrm{l}$. Figure 5 shows a tracing of the sensor current and the corresponding blood glucose levels in a normal subject displaying this phenomenon.

The hypoglycaemia-associated oscillations in sensor output also occurred in diabetic patients. Figure 6 shows the current tracing and the glycaemic values from a patient who became spontaneously hypoglycaemic during a study. This 32 -year-old patient with a duration of diabetes of 10 years, had lost warning symptoms of hypoglycaemia and was completely unaware of the low glucose levels. 

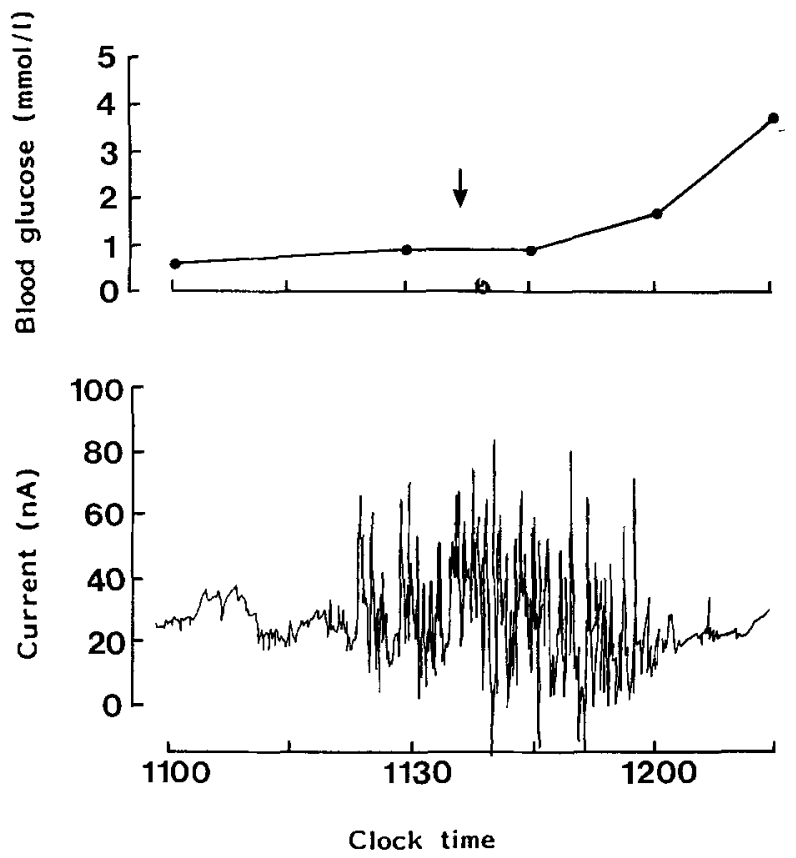

Fig. 6. Blood glucose concentrations (O) and a tracing from the current output of a sensor implanted in the subcutaneous tissue of an insulin - dependent diabetic subject. Note oscillations in the sensor current occurring during spontaneous hypoglycaemia. $\downarrow$ indicates time of administration of food

\section{Discussion}

It has been suggested $[1,3,6]$ that ferrocene-mediated electron transfer would be a suitable technology for implantable glucose sensors in man because the low operating potential ( $160 \mathrm{mV}$ for the dimethyl derivative) may minimise interference from co-reactants such as ascorbic acid, the dependence on oxygen should be small (because dioxygen is not the final electron acceptor), the response is fast, $\mathrm{pH}$ - independent and linear to adequately high glucose levels, and the ferrocene is water - insoluble and thus easily held at the electrode.

In the present study, we have provided preliminary details of the operation of such sensors in normal and insulin-dependent diabetic subjects when implanted in the subcutaneous tissue. The current output of the sensor followed changes in blood glucose concentrations, albeit with damping of the responses and a delay in peaks and nadirs with respect to the glycaemic values. In the pig, we also found [3] significantly slower increases and decreases in electrode-measured tissue glucose concentrations, compared to blood levels. Nevertheless, the formulation of suitable algorithms relating sensor and blood responses should allow detection of hypoglycaemia on most occasions.

Interestingly, a recent report [7] of glucose sensors used in normal subjects during a hyperglycaemic clamp demonstrated virtually no lag between sensor and blood readings. The reason for this discrepancy is unclear but factors such as sensing site, adiposity and sensor dimensions may be important and should be explored. In these preliminary studies, it is not possible to assess the contribution of in vivo electrode drift to the kinetics; we do not consider that pre-implantation and post-implantation calibration curves can be used as a measure of electrode decline since sensor coating and perhaps damage during the insertion process may alter characteristics in an unknown and unpredictable way.

The design of the present sensor has been shown to be stable in vitro over at least an $18 \mathrm{~h}$ period $[4,5]$ which is sufficient for its eventual application as a nocturnal hypoglycaemia alarm. The mechanism of the stability may involve contributions from increased enzyme loading, better retention of the enzyme by covalent linking to agarose beads and an increased diffusion barrier imposed by the agarose gel. In the studies reported here, in vivo operation was demonstrated over only a few hours; it will be important in future work to confirm stability of the implanted device over periods of $18-24 \mathrm{~h}$.

The calibration of in vivo glucose sensors is an unresolved problem. In several previous studies [3, 8-10] in vitro calibrated electrodes of various constructions have recorded an apparently lower subcutaneous tissue glucose than the simultaneously measured blood or plasma glucose concentration. For example, we reported [3] that the mean ratio of blood/subcutaneous tissue glucose concentration was 5.2 in the pig but this varied widely with different animals and electrodes (range 1.8-14.7). Fischer et al. [11] have recently shown that, in the dog, true interstitial glucose levels, measured by obtaining fluid from $0.154 \mathrm{~mol} / 1 \mathrm{NaCl}$ soaked and subcutaneously implanted wicks, were almost identical to blood values, in contrast to sensors initially calibrated in vitro which recorded glucose concentrations between 70 and $90 \%$ of blood values.

The inconsistency of the blood/tissue ratio in the present study may indicate that prior in vitro calibration is unsatisfactory for implanted sensors and we, therefore, used the initial blood glucose concentration as a reference, as recommended by Fischer et al. [11]. There are two possible problems with this approach. Firstly, in diabetic subjects tissue glucose levels are not necessarily in steady or near-steady state at this time. Secondly, a two-point calibration (at two constant blood glucose levels) ideally is required to compensate for any discrepancy between the in vitro and in vivo background currents [12]. Such an approach seems impracticable under everyday circumstances, but the value of a simple, one-point calibration will have to be proved by extensive clinical trials demonstrating the power of such a calibrated sensor to detect hypoglycaemia.

In this study, we also noted marked and rapid oscillations in the sensor current in many subjects, beginning as the blood glucose fell below about $1.9 \mathrm{mmol} / 1$. One may speculate that these may have been caused by variations in subcutaneous blood flow or underlying muscle tremor, mediated perhaps by the hormonal and/or neuronal counter-regulatory responses to hypo- 
glycaemia. However, a diabetic patient who did not experience any warning symptoms of hypoglycaemia and who presumably did not have substantial adrenergic responses [2] also demonstrated these oscillations during a period of spontaneous hypoglycaemia. Exudative reactions have been reported by other workers at glucose sensor implantation sites in dogs, after many hours [13]. Though it is possible that this phenomenon may be contributing to the oscillations in our studies, we think this unlikely because the fluctuations occurred within an hour of implantation, were activated in both electrodes in the same person at the same time, and were stopped by the administration of glucose or food, there was no macroscopic evidence of exudation, oscillations occurred in a hypoglycaemic patient at the start of implantation and were not present after the administration of an oral glucose load. The mechanisms of these current fluctuations, therefore, and their possible value as a marker of hypoglycaemia need further study.

Finally, the realisation of implantable glucose sensors as devices for routine use in diabetes care will depend primarily on obtaining good shelf-life, and operating stability and reliability. Ferrocene-mediated sensors are amongst the first of the attempts to produce new types of electrodes for clinical use but alternative technologies should continue to be explored. Recent promising approaches which deserve study include the use of new enzymes such as the NAD-independent quinoprotein glucose dehydrogenase [14] and new mediators or electrode materials such as the organic metal tetrathiafulvalene tetracyanoquinodimethane $[15,16]$. By focusing on the important clinical need for hypoglycaemia detection and correction, sensor stability can be optimised in the first instance over a relatively short period [4] and, in combination with new bioelectronic strategies, in vivo sensing in diabetes may at last be brought within the realms of possibility.

Acknowledgements. We are grateful to the Juvenile Diabetes Foundation International and the British Diabetic Association and the Central Fund of the University of London for financial support.

\section{References}

1. Pickup JC (1985) Biosensors: a clinical perspective. Lancet II: 817-820

2. Anon (1987) Awareness of hypoglycaemia in diabetes. Lancet II: 371-372
3. Claremont DJ, Sambrook IE, Penton C, Pickup IC (1986) Subcutaneous implantation of a ferrocene-mediated glucose sensor in pigs. Diabetologia 29: 817-821

4. Pickup JC, Shaw GW, Claremont DJ (1989) Potentially - implantable amperometric glucose sensors with mediated electron transfer: improving the operating stability. Biosensors in press

5. Claremont DJ, Shaw GW, Pickup JC (1988) Improving the stability of potentially-implantable glucose sensors. Diabetic Med 5 [Suppl.]: $2 \mathrm{~A}$

6. Cass AEG, Davis G, Francis GD, Hill HAO, Aston WJ, Higgins IJ, Plotkin EV, Scott LDL, Turner APF (1984) Ferrocene-mediated enzyme electrode for amperometric determination of glucose. Anal Chem 56: 667-671

7. Matthews DR, Bown E, Beck TW, Plotkin E, Lock L, Gosden E, Wickham M (1988) An amperometric needle-type glucose sensor tested in rats and man. Diabetic Med 5:248-252

8. Bessman SP, Thomas LJ, Kojiima H, Sayler DF, Layne EC (1981) The implantation of a closed-loop artifical beta cell in dogs. Trans Am Soc Art Int Org 27: 7-17

9. Abel P, Miller A, Fischer U (1984) Experience with an implantable glucose sensor as a prerequisite of an artificial beta cell. Biomed Biochim Acta 5: 577-584

10. Shichiri M, Kawamori R (1983) Feasibility of a needle-type glucose sensor and the wearable artifical endocrine pancreas system in human diabetic subjects. In: Irsigler K, Kritz, Lovett R (eds) Diabetes treatment with implantable insulin infusion systems, Urban \& Schwarzenberg, Munich, pp 224-230

11. Fischer U, Ertle R, Abel P, Rebrin K, Brunstein E, Hahn von Dorsche H, Freyse EJ (1987) Assessment of subcutaneous glucose concentration: validation of the wick technique as a reference for implanted electrochemical sensors in normal and diabetic dogs. Diabetologia 30: 940-945

12. Velho G, Froguel P, Reach $G$, Thevenot D (1987) In vivo calibration of a needle-type glucose sensor to determine the kinetics of subcutaneous glucose concentration. Diabetologia 30: 592 A

13. Rebrin K, Fischer U, Woedtke TV, Brunstein E, Abel P (1988) Tissue glucose telemetry and control in normal and diabetic dogs. Diabetologia 31: 534A

14. D'Costa EJ, Higgins IJ, Turner APF (1986) Quinoprotein glucose dehydrogenase and its application in an amperometric glucose sensor. Biosensors 2: 71-87

15. Kulys JJ (1986) Enzyme electrodes based on organic metals Biosensors 2: 3-13

16. Albery WJ, Bartlett PN, Craston DH (1985) Amperometric enzyme electrodes II. Conducting salts as electrode materials for the oxidation of glucose oxidase. J Electroanal Chem 194: $223-235$

Received: 15 November 1988

and in revised form: 31 January 1989

Dr. J.C. Pickup

Division of Chemical Pathology

United Medical and Dental Schools

Guy's Hospital

London SE1 9RT

UK 